\title{
Wrap-and-strip technology of protein-polyelectrolyte complex for biomedical application
}

\author{
Kentaro Shiraki*,1, Takaaki Kurinomaru ${ }^{1}$, Shunsuke Tomita ${ }^{2}$
}

${ }^{1}$ Faculty of Pure and Applied Sciences, University of Tsukuba, 1-1-1 Tennodai, Tsukuba, Ibaraki 305-8573, Japan

${ }^{2}$ Biomedical Research Institute, National Institute of Advanced Industrial Science and Technology, 1-1-1 Higashi, Tsukuba, Ibaraki 305-8566, Japan

\begin{abstract}
A polyelectrolyte is a polymer composed of repeating units of an electrolyte group that enables reversible complex formation with proteins in aqueous solutions. This review introduces "wrap-and-strip" technology of protein-polyelectrolyte complex (PPC) by noncovalent interaction. Storage: protein is stabilized against physical and chemical stresses. Enrichment: precipitation through PPC can be used as an enrichment method without irreversible unfolding. Catalytic activity switch: a complementary charged pair of polyelectrolytes functions as a reversible enzyme activity switch. Hyperactivation: a specific combination of a polyelectrolyte and substrate enhances enzyme activity by one order of magnitude compared with an enzyme alone. Stabilization: PPC increases protein stability against chemical and physical stresses, such as covalently modified polyethylene glycosylated protein. Simple PPC-based technology can expand the applicable fields of soluble proteins in aqueous solutions
\end{abstract}

Keywords: Antibody; enzyme; enrichment; polyelectrolyte; enzyme activity; aggregation; precipitation

Address correspondence to this author at the Faculty of Pure and Applied Sciences, University of Tsukuba, 1-1-1 Tennodai, Tsukuba, Ibaraki, 305-8573, Japan; Fax: +81-29-853-5215; Tel: +81-29-853-5306; E-mail: shiraki@bk.tsukuba.ac.jp

\section{INTRODUCTION}

Protein has a unique function depending on its tertiary structure in aqueous solutions. To control the protein structure and function, there is a need to understand a broad range of protein phenomena, including protein folding and misfolding, aggregation, thermal and thermodynamic stability, protease and other chemical degradation, and mechanisms of enzyme activity, and protein-ligand interactions. Small-molecular-weight compounds have been developed as additives that control protein stability and aggregation in bulk solutions. An osmolyte is a structural stabilizer of protein excluded on the protein surface, such as glycerol, sugar, polyol, betaine, and trimethylamine-N-oxide [1] by preferential hydration of the protein [2]. In contrast, small molecules that bind preferentially to the protein surface lead to protein unfolding, as is typically the case for guanidine hydrochloride and urea [3]. Being different from these denaturants, the weak denaturing effect of additives is rather favorable as with aggregation suppressors, such as arginine ethylester [4], arginine amide [5], amino acid alkylesters [6], amidated amino acids [7], diamines 
[8], and naturally occurring polyamines [9]. The aggregation suppressors of these small compounds have generally small electrolytes that bind weakly to the protein surface [10]. For the development of aggregation suppressors, it is generally believed that polymers of the polyelectrolyte interact more strongly with protein than its monomer units, leading to better control of protein folding and stability.

In this review, we introduce recent advances in the protein-polyelectrolyte complex (PPC) on protein stability and function (Figure 1). Note that this review describes only synthetic and liner polyelectrolytes. A polyelectrolyte consists of repeating units of a positively or negatively charged group, which enables a complex formation with protein in aqueous solutions through multiple electrostatic interactions. We classified PPCs under two states, insoluble PPC and soluble PPC. Insoluble PPC is a clouded state due to the less electrostatic repulsion between protein-polyelectrolyte complexes. In contrast, soluble PPC is a transparent solution of protein-polyelectrolyte complex with a diameter of $<200 \mathrm{~nm}$. As PPC with two different states are basically formed depending on both the properties of proteins or polyelectrolytes and solution conditions, e.g., $\mathrm{pH}$ and ionic strength, PPC can easily be solubilized by introducing aggregation-suppressive segment, e.g., poly(ethylene glycol) (PEG), to proteins or polyelectrolytes. The crucial element of polyelectrolyte applications is the reversibility of PPC.

Proteins are "wrapped" in counter-charged polyelectrolytes and then "stripped" from the formed PPC by responding to various stimuli. The wrap-and-strip technologies are classified into five types of applications as follows: A protein-polyelectrolyte combination pair leads to the formation of precipitates. The precipitated state of the PPC stabilizes proteins against physical and chemical stresses (Figure 1a). Importantly, the precipitated PPC is dissolved by the addition of physiological saline and/or other polyelectrolytes. Thus, PPC precipitation is a simple method for the enrichment of protein from a diluted solution (Figure 1b). In contrast, some kinds of polyelectrolytes wrap the protein surface without forming insoluble precipitates. Soluble PPC formation can be used as an "on-off" switch for enzyme activity in aqueous solutions (Figure 1c). The polyelectrolyte-wrapped enzyme enhances its enzyme activity towards a specific substrate increased by one order of magnitude, relative to the same enzyme without polyelectrolyte wrapping (Figure 1d). A soluble PPC has also been developed to improve protein stability in aqueous solutions against heating and other chemical stresses (Figure 1e), similar to poly(ethylene glycol)-modified antibodies. Insoluble and soluble PPC-based technologies can be employed to expand the range of proteins available for application and their ease of use, owing to their ability to form non-covalent electrostatic-driven complexes in aqueous solutions.

\section{PROTEIN-POLYELECTROLYTE COMPLEX}

Protein polyelectrolyte complex (PPC) was first described more than a half century ago [11], defined as a complex of proteins with polyelectrolytes stabilized by electrostatic interactions. Morawetz and Hughes demonstrated that bovine serum albumin could form precipitates with an acidic polyelectrolyte of poly(metacrylic acid). Thereafter, other groups were inspired to expand the use of PPC beyond its original 
application, rapid protein purification, and separation [12]. A comprehensive review by Cooper et al. [13] and the update by Kayitmazer et al. emphasize the rapid advances in ongoing methodology and theory toward medical, pharmaceutical, and nanotechnological applications of PPCs [14].

PPCs are observed and applied in various fields, for example, a soluble complex of hemoglobin with dextran sulfate [15], an insoluble complex of hemoglobin with poly(diallyldimethylammonium chloride) [16], a nano-sized particle from $\beta$-lactoglobulin with an anionic polysaccharide pectin for food chemistry [17], and a coating film on paper of whey protein and chitosan [18]. From the medical point of view, block copolymer micelles are the most successful application in drug delivery systems [19], such as micelles encapsulated by a pH-sensitive smart polymer for antibodies [20] and small RNAs [21]. Other possible applications in a technological context are multilayered assemblies of globular proteins by layer-by-layer adsorption [22], fibroin protein in complexes with chitosan for the scaffolds of tissue engineering [23], a responsive photoreactor triggered by PPC formation with thin polymer film [24], enzyme immobilization on polyelectrolyte brushes on a solid surface [25], and protein separation by polyelectrolyte coated capillary electrophoresis [26]. More simple complex formation has been observed for highly branched polyamidoamine with prion peptide (185-208) and amyloid beta (1-28) [27]. Thus, these polyelectrolyte applications have expanded the feasibility of prominent protein functions.

It is noted that the similar term "polyion complex" emerged in 1960s, around the same time as "protein-polyelectrolyte complex," coined by Michaels and co-workers [28]. They demonstrated that a cationic polymer poly-(vinylbenzyltrimethylammonium chloride) formed insoluble hydrous precipitant with an anionic polymer poly-(styrenesulfonate) with a randomly twisted pair. Subsequently, they revealed that the stabilization of PPC showed dielectric properties via counterions [29]. Although the polyelectrolyte complex is generally termed a "polyion complex," in some cases, proteins are the only component of the complex, because many proteins are also polyelectrolytes. On the other hand, Kabanov and co-workers have used the term "block ionomer complex" for complexes between polyethylene glycosylated polyelectrolytes and complementary charged molecules, including proteins [30]. In this review, we integrated the term PPC in reference to all cases.

\subsection{Precipitated PPC}

The first example of wrap-and-strip technology with precipitated PPC is facile and widely applicable to storage and enrichment methods (Figure 1). As described in this section, once proteins are precipitated through PPC formation, the protein function maintains for a long time and even shows higher resistance against chemical and physical stresses, such as heat, agitation and oxidation; the unexpected results will be beneficial for pharmaceutical and biotechnological applications of proteins. The pellet state formed by centrifugation of the PPC can be used for an enrichment method because the protein can be released by physiological concentrations of salts. Applications of precipitated PPC are described as follows. 


\subsubsection{Storage by precipitated PPC without lyophilization}

Lyophilization, or freeze-drying, is the most common method used for storage of proteins. A protein solution is frozen, and the bound water is subsequently dried under vacuum [31]. The solid-state protein shows higher stability against chemical degradation compared with that of the solution-state. However, the processes of both freezing and drying are detrimental to protein structure, leading to irreversible unfolding. When we would like to stabilize and store protein, it is more favorable for the protein to remain in solution under physiological conditions. Combining a polyelectrolyte with protein leads to precipitate formation. The precipitated PPC are used to stabilize the protein in aqueous solutions (Figure 1a).

One of the applications of PPC is the combination of pharmaceutical proteins with poly(amino acid). In brief, the monoclonal antibody drugs, adalimumab (Humira for autoimmune disease; $\mathrm{p} I=8.7$ ) and omalizumab (Xolair for allergic asthma; $\mathrm{p} I=7.6$ ) were allowed to form complexes with poly(glutamic acid) of 3-15 kDa average molecular weight (polyE; $\mathrm{p} K_{\mathrm{a}}=3.9$ ) in $10 \mathrm{mM}$ MOPS (pH 6.5) and $10 \mathrm{mM}$ Na-citrate buffer ( $\mathrm{pH}$ 5.5), respectively [32]. Note that the weight percentage of polyE is only $5 \%$ antibody. The precipitated-state antibodies were protected agitation-induced aggregation at $500 \mathrm{rpm}$ for $60 \mathrm{~h}$ [33]. The residual immunoreactivities of native adalimumab were $20.7 \%(0.5 \mathrm{mg} / \mathrm{ml}$ antibody $)$ and $53.8 \%(5.0 \mathrm{mg} / \mathrm{ml})$ following agitation, while those of polyE complex precipitation remained at approximately $100 \%$. More importantly, the protein aggregates as part of the polyE complex were smaller in size than those without polyE following exposure to agitation stress [34].

Similar resistance was observed in the enzyme, L-asparaginase (Leunase for acute lymphoblastic leukemia; $\mathrm{p} I=4.7$ ), when in complexes with poly(lysine) (polyK; $\mathrm{p} K_{\mathrm{a}}=10.5$ ) of $4-5 \mathrm{kDa}$ average molecular weight in $10 \mathrm{mM}$ MOPS buffer $(\mathrm{pH} \mathrm{7.0)}$ [34]. L-Asparaginase-polyK precipitates also showed higher resistance to thermal inactivation, agitation, and oxidation. Such a precipitated state with poly(amino acid) may be a new candidate method for the storage of antibodies and enzymes as another storage method due to the simplicity and low cost without freezing and/or drying process. When used as protein stabilizers, small molecules should be at high concentrations (typically several hundred $\mathrm{mM}$ ) because of their low binding energies, while polyelectrolytes, which bind specifically to the protein surface, may be used in vivo. Note that poly amino acids are generally biocompatible; actually, polyE with average molecular weight of 50-100 kDa complexed with IgG and Omalizumab did not show general toxicity in rats for 20 days [35]. Further feasibility should be checked for the application of polyelectrolytes-protein complex in future.

\subsubsection{Enrichment by precipitated PPC for high-concentration formulation of antibody}

The enrichment (or concentration) of protein is a problematic process because of the protein's viscosity and potential for unfolding. In general, therapeutic antibodies for subcutaneous injection require several hundred mg per dose, while injection volumes above $1.5 \mathrm{~mL}$ are not permitted by the US Food and Drug Administration (FDA) [36]. However, high concentrations of protein (typically $200 \mathrm{mg} / \mathrm{ml}$ ) increase 
the non-covalent network formation between proteins, leading to a drastic increase in solution viscosity [37]. A viscosity of $50 \mathrm{cP}$ is an acceptable threshold for subcutaneous injection. Such a high concentration of protein also causes a serious problem for formulation, processing, and storage by way of undesirable aggregation.

Several types of enrichment methods have been developed [38]. Ultrafiltration is the most popular method for the enrichment of protein in solution, but flow and pressure should be strictly regulated and controlled to minimize protein aggregation during concentration [39]. In contrast, the addition of small solvent additives, such as inorganic salts [40], hydrophobic salts [41], and amino acid hydrochlorides, is the simplest method used to decrease solution viscosity [42]. Arginine is a good candidate to reduce the viscosity of antibodies at high concentration [43]. Liquid-liquid phase separation from an isotonic to a low ionic strength condition is a new candidate for the high-concentration formulation of antibody [44].

Crystallization of antibody is another approach in which the patient is dosed with sufficient amounts of protein by subcutaneous administration to avoid the viscosity problem [45]. Such crystalline-state protein is pristine without impurities or aggregates, but the crystallization itself is time-consuming and the preparation of sufficient quantities of protein is difficult. A similar mechanism has been proposed using the nanoparticle dispersion of the protein-cluster state [46]. Johnston et al., have demonstrated that 1B7 antibody in a high-concentration trehalose solution forms a kind of protein colloid with a diameter of 50-300 nm via short-range hydrophobic interactions. The protein-cluster states disperse in solution by long-range electrostatic repulsion without protein denaturation. Another approach involved the use of gel beads that were associated with a protein concentration of $180 \mathrm{mg} / \mathrm{ml}$ for monoclonal antibody purification [47]. The solid-state therapeutic protein has an attractive potential to suppress dose volume for subcutaneous injection.

PPC formation is a useful phenomenon for the enrichment of therapeutic proteins for highconcentration formulation (Figure 1b). The precipitated state of PPC is a kind of protein solid that reduces the dose volume of therapeutic proteins (Figure 2). In brief, a protein suspension is obtained by mixing the protein solution with poly(amino acid) of low ionic strength [32]. Thereafter, the precipitated protein is obtained by centrifugation. The pellet-state protein-poly(amino acid) complex is easily dissolved by inorganic salt at physiological concentration, typically $150 \mathrm{mM} \mathrm{NaCl}$. Thus, the driving force behind protein-poly(amino acid) complex formation is mainly electrostatic interaction. Note that the resolubilized-state protein displays its original function and structure, as is the case with various kinds of proteins, such as the therapeutic monoclonal antibodies of Panitumumab, Etanercept, Adalimumab, Infliximab, Omalizumab, and Rituximab; the peptide hormone of Carperitide; the enzyme drug of L-asparaginase; and the globins of thyroglobulin and immunoglobulin G [32-34]. The recovery of activity and secondary structure implies that the process of PPC precipitation does not affect the tertiary structure of protein. Actually, Omalizumab-polyE precipitates showed identical efficacy of a drug to Omalizumab alone, without a side effect of toxicity [35]. 
The design of solution conditions for PPC follows some simple rules for mixing ratio and solution $\mathrm{pH}$. Anionic poly(glutamic acid) or cationic poly(lysine) of 1.5-30 kDa are added to the protein solution at a mass ratio of about 1:10 or 2:10. The solution $\mathrm{pH}$ is about two $\mathrm{pH}$ units higher or lower than the isoelectric point of protein, for example, a Tris-HCl buffer ( $\mathrm{pH}$ 8.7) with poly(lysine) is favorable for Panitumumab (pI = 6.9), while a citrate buffer ( $\mathrm{pH} 5.5$ ) is favorable for Omalizumab ( $\mathrm{p} I=8.7$ ). It is noted that the precipitation and resolubilization method using a protein-poly(amino acid) complex can be scale up from $0.4 \mathrm{~mL}$ to $1.0 \mathrm{~L}$ [35]. It is known that some antibodies start to aggregate under low ionic strength. In this case, the antibody solution in high concentration $\mathrm{NaCl}$ was mixed with large amount of low ionic strength solution with polyelectrolyte. This is because PPC precipitation can easily be separated by centrifugation. In addition, precipitated PPCs take on various shapes and morphologies, such as white granules and transparency gel-like precipitates, depending on the types of protein and solution conditions, though all of the precipitates can be solubilized by $\mathrm{NaCl}$ at physiological concentration. The reasons for which different precipitates form will be clarified in the future.

\subsection{Soluble PPC}

A combination of protein and polyelectrolyte forms soluble PPC. Soluble PPCs can also expand the feasibility of protein function and stability (Figure 1). Importantly, the soluble PPC is also stripped off by the addition of polyelectrolyte. Reversible PPC formation in vitro accomplishes catalytic activity switch, hyperactivation, and stabilization of proteins, as follows.

\subsubsection{Catalytic activity switch by soluble PPC}

Figure 3 shows the "on-off” enzyme switch by wrap-and-strip technology using two kinds of oppositely charged polyelectrolytes. The addition of a polyelectrolyte (cationic, in this case) wraps a protein surface (anionic, in this case). Under the "off" condition, the protein is inactivated due to blocking of the active site or a slight structural deviation. Then, the addition of alternatively charged polyelectrolyte (anionic, in this case) strips off the bound polyelectrolyte on the protein surface, releasing and consequently, reactivating the protein.

The enzyme switch by polyelectrolytes has been indicated by Shalova et al [48]. The paper demonstrated that the heat-treated PPC between glyceraldehyde-3-phosphate dehydrogenase (GAPDH) and anionic polymers of poly(methacrylic acid) and sodium poly(styrene sulfonate) was partially reactivated by addition of strong polycation poly( $\mathrm{N}$ - ethyl-4-vinyl pyridinium) bromide. The fully inactivate-reactivate switch of enzyme activity has been reported by a set of polyelectrolytes of poly(acrylic acid) (PAAc) (5.0 $\mathrm{kDa})$ and poly(allylamine) (PAA) (5.0 kDa) [49]. The demonstration was performed using bovine ribonuclease A (13.7 kDa, $\mathrm{pI}=9.9)$, hen egg white lysozyme (14.3 $\mathrm{kDa}, \mathrm{p} I=11.0)$, Aspergillus niger cellulase (24.3 kDa, $\mathrm{p} I=4.1)$, and Aspergillus oryzae $\alpha$-amylase (52.4 kDa, $\mathrm{p} I=4.2)$ as model proteins. An 
anionic polymer, PAAc wraps up cationic ribonuclease A and lysozyme, leading to full inactivation of the enzymes. This is the "off" state of enzyme activity. Then, the addition of cationic polymer, PAA strips off the bound PAAc, leading to the recovery of enzyme activities. This is "on" state of enzyme activity. The approach was applicable to small and stable proteins without affecting its tertiary structure, but large and unstable proteins, such as alpha-amylase and beta-galactosidase [50], were switched-off but simultaneously denatured through PPC formations after long-time incubation due to physical stress derived from aggregate formation. This issue was addressed by the introduction of aggregate-suppressive segment to polyelectrolytes (see Section 2.2.3).

The mechanism of enzyme switch was quantitatively analyzed using enzyme kinetics [51]. Bovine ribonuclease A, hen egg white lysozyme, and bovine trypsin (25.3 kDa, $\mathrm{p} I=9.5)$ were used as model proteins and anionic PAAc with an average of molecular mass of $5.0 \mathrm{kDa}$ (70 structural units) was used as the polyelectrolyte for PPC. Enzyme activities decreased with increasing concentration of PAAc as a noncompetitive inhibitor for all of the enzymes. Dissociation constants for the enzyme-polymer interactions were in the order of $10^{-8} \mathrm{M}$, whereas the secondary structures of all enzymes remained unchanged. The binding numbers of PAAc molecules per one protein molecule were calculated 3.0 for ribonuclease A, 7.5 for lysozyme, and 8.8 for trypsin. If binding depends mainly on the electrostatic interactions between positively charged protein and negatively charged PAAc, then the order of binding numbers should be lysozyme > ribonuclease A > trypsin. Thus, the binding affinity between protein and polyelectrolyte is dependent not only on electrostatic interactions, but also on other factors. One of the plausible causes of binding between protein and polyelectrolyte is the hydrophobicity of the protein surface. When water molecules bound to the hydrophobic surface are released during complex formation between the protein and the polyelectrolyte, entropy gain is a driving force between the protein and the polymer [52]; this entropy-driven system is similar to protein folding [53]. Ballauff and co-workers recently revealed the entropic contribution of PAAc and human serum albumin using isothermal titration calorimetry and theoretical simulation [54].

Reversible PPC formation prompts us to develop new types of applications. One such application is the optical cross-reactive sensor array (Figure 4a). This sensor array, inspired by the gustatory and olfactory systems [55], utilizes an array of cross-reactive receptor molecules to produce unique optical fingerprints for target analytes [56]. Multivariate analysis of the fingerprints obtained by this method has enabled us to discern a variety of analytes, such as proteins in human serum [57, 58] or urine [59]. Figure $4 \mathrm{~b}$ shows a sensor array consisting of PPCs. The inhibited anionic enzymes, $\alpha$-amylase and $\beta$-galactosidase, through complex formation with cationic polyelectrolyte poly(ethylene glycol)-block-poly( $N, N$-dimethylaminoethyl methacrylate) (PEG-b-PAMA) were recovered by the addition of analyte proteins. As the amount of activity recovery depended on binding competition among polyelectrolytes, enzymes and proteins, fingerprints of changes in enzyme activity for individual analyte proteins were generated. Seven kinds of serum proteins in the order of $100 \mathrm{nM}$ were identified by a kind of multivariate analysis [60]. This highly discriminative fingerprinting approach can also be used to identify four kinds of homologous mammalian albumins from bovine, equine, human, and rabbit sources [61], 
mammalian sera [62], and secreted proteins from differentiated mesenchymal stem cells [63].

\subsubsection{Hyperactivation of enzymes by soluble PPC}

PPC formation generally inhibits protein activity. In contrast, protein activity can be increased rather substantially by a specific combination of substrate and polyelectrolyte (Figure 1d), a phenomenon referred to as enzyme hyperactivation. The first incidence of enzyme hyperactivation by PPC was reported in bovine $\alpha$-chymotrypsin $(25.2 \mathrm{kDa}, \mathrm{p} I=8.1)$ with the combination of an anionic polyelectrolyte of PAAc and a cationic substrate of $N$-glycyl-L-phenylalanine-p-nitroanilide [64]. The activity of $\alpha$-chymotrypsin toward the cationic substrate in the presence of PAAc was 7-fold higher than that in the absence of PAAc. Similarly, the enzyme activity of $\alpha$-chymotrypsin toward an anionic substrate $N$-succinyl-L-phenylalanine- $p$-nitroanilide with a cationic polyelectrolyte PAA was shown to be 18-fold higher than that in the absence of PAA. The mixtures of $\alpha$-chymotrypsin with PAAc and PAA showed hydrodynamic diameters of $10.0 \mathrm{~nm}$ and $6.7 \mathrm{~nm}$, respectively, which were slightly larger values compared with that of $\alpha$-chymotrypsin alone $(5.1 \mathrm{~nm})$. Thus, $\alpha$-chymotrypsin likely formed complexes with these polyelectrolytes. In fact, negatively charged residues on the localized surface of the protein could bind to the positively charged polymer via electrostatic interactions [65]. Michaelis constants $\left(K_{\mathrm{M}}\right)$ of $\alpha$-chymotrypsin-PAAc and $\alpha$-chymotrypsin-PAA decreased 8-fold and 3-fold, respectively, compared with that of $\alpha$-chymotrypsin alone. Thus, electrostatic interactions between the protein and the wrapping polyelectrolyte play a crucial role in the hyperactivation of the enzyme. This idea was supported by data showing that enzyme activity decreased with increasing concentration of $\mathrm{NaCl}$; hyperactivation was not observed at a concentration of $300 \mathrm{mM} \mathrm{NaCl}$ [64]. This is because electrostatic interactions among the enzyme, polyelectrolyte, and substrate play an important role in hyperactivation.

Harada and co-workers have shown that the enzyme activity of bovine trypsin toward a cationic small substrate of L-lysine-p-nitroanilide increased in the presence of poly(ethylene glycol)-block-poly(aspartic acid) (PEG-PAsp) [62]. The $k_{\text {cat }} / K_{\mathrm{M}}$ value of trypsin with the mixing ratio of PEG-PAsp of 10 equivalents was shown to be 8-fold higher than that in the absence of the polyelectrolyte. Interestingly, this activation was only related to the increase in the $k_{\text {cat }}$ value. The author concluded that PEG-PAsp stabilized the imidazolium ion of His in the catalytic site. In fact, the electrostatic field around the catalytic triad is indispensable for the activation of serine proteases $[67,68]$.

It is interesting to show that small amine compounds, such as naturally occurring spermine, spermidine, and putrescine [69], and quaternary ammonium salts with methyl, ethyl, propyl, and butyl groups [70], increase the activity of $\alpha$-chymotrypsin 1.6-fold to 6.9-fold. Hyperactivation by small amine compounds is mainly due to favorable charge-charge interactions between substrate and additive, which is different from the micelle-like structure of additives [71, 72]. In fact, the systematic analysis of 12 kinds of small amine compounds showed that the enzyme activity of $\alpha$-chymotrypsin increases with both increasing hydrophobicity and charge number of the small polyelectrolyte additives [69]. Taken together, these lines of 
evidence demonstrate that polyelectrolytes enhance the enzyme activity of $\alpha$-chymotrypsin toward complementary charged substrates. The mechanism governing hyperactivation may be simple: charged polyelectrolytes act as an electrostatic scaffold that increases the local concentration of the oppositely charged substrate around the active site.

\subsubsection{Stabilization of protein by PEGylated polymer}

The examples described above involve the use of homo-polyelectrolytes, whereas incorporating PEG chemistry brought different technologies based on PPC formation for protein manipulation. PEG is one of the most beneficial polymers used with protein in various fields due to its non-toxicity, high chemical stability, high solubility, low cost, and lack of other negative influences on protein structure and function. The conjugation of PEG protein by covalent modification (so called PEGylated protein) was first suggested in 1977 [73]. PEGylation of protein actually improves protease-resistance [74] while increasing circulation in blood [75], increasing solubility, and suppressing aggregation [76], and other favorable properties reviewed in the early stages of pharmaceutical drug development [77]. Today, the FDA has approved many PEGylated proteins as therapeutics, such as the enzymes, adenosine deaminase, asparginase, and uricase; interferon; growth hormone; antibody fragment; and aptamer [78]. PEGylated proteins increase the pharmacological stability via steric shielding of protein against protease digestion and non-specific aggregate formation. Furthermore, covalently-PEGylated proteins in pharmaceuticals reduce antigenicity, immunogenicity, and proteolytic degradation [79, 80], although a part of people has anti-PEG antibody that inactivates administrated PEGylated protein and in some cases induces allergy reaction. These properties are attributed to steric hindrance of the interactions between proteins by soluble PEG chains on the protein. However, PEGylation decreases the bioactivity of several proteins, notably insulin.

Consequently, non-covalent protein-polymer complexes have been proposed for insulin improvement as an alternative to the covalent approach. PEG is a hydrophilic polymer that lacks a charged group, and hence PEG cannot bind to the protein surface by noncovalent interaction. Thus, non-covalent protein-polymer complexation requires PEG-derivative synthesis with another segment that can recognize proteins through hydrophobic and/or electrostatic interactions. In other words, PEG segments play an important role for the suppression of protein aggregation, rather than binding on protein surface. A PEG derivative of dansyl-methoxypoly(ethylene glycol) (mPEG) with an average molecular weight of $2 \mathrm{kDa}$ successfully bound to salmon calcitonin [81]. Several kinds of dansyl, tryptophan, phenyl, benzyl, and cholesteryl-mPEGs revealed that the hydrophobic dansyl head binds to protein surfaces in hydrophobic patches without protein denaturation, leading to a decrease in the aggregation propensity of the calcitonin and hen egg-white lysozyme [82]. Metal ions can bind histidine residues of proteins, a phenomenon referred to as metal-chelate affinity. This type of binding is applied to other principles of noncovalent PEGylation between protein and PEG derivatives: PEGylated nitrilotriacetic acid with $\mathrm{Cu}^{2+}$ metal ions bound to hemoglobin, human growth hormone, interferon, insulin, and granulocyte colony stimulating factor [83]. This type of specific binding has been reported for the other protein-PEGylated polymers, such as 
biotin-PEGylated peptide with avidin [84], PEGylated polyanions, pentosan polysulfate, and dextran sulfate toward a heparin-binding protein of repifermin [85].

Electrostatic interactions between a protein and a PEGylated polymer represent a predominant design principle that stabilizes noncovalent binding with protein (Figure 1e). A triblock copolymer of PEG-(fumaric-sebacic acids)-PEG binds to human and bovine insulin with an electrostatic association constant in the order of $10^{4}$ [86]. Chitosan-coated mesoporous silicon microparticles are a biodegradable material with the binding capacity of insulin and albumin [87, 88]. Cationic polymers of PEGylated oligolysine and oligoarginine can bind to insulin with high ( $>95 \%)$ levels of complex formation efficiency [89]. The PEGylated oligopeptides also have the advantage of being biodegradable, but they tend to form aggregates with insulin, as analyzed by isothermal titration calorimetry and Fourier transform infrared spectroscopy. A comb-shaped amphiphilic poly(allylamine) can bind to insulin with efficiencies of 78\%-93\% [90]. Complex formation with the polymer can protect it from proteolysis by trypsin and pepsin.

Figure 5 shows the protein stabilization strategy using PEG with covalent modification or noncovalent interaction. L-Asparaginase is one of the therapeutic enzymes prescribed for acute lymphoblastic leukemia [91], with a tetrameric form of identical $35.6 \mathrm{kDa}$ subunits [92, 93]. An anionic L-asparaginase at neutral $\mathrm{pH}$ was bound to a cationic poly(ethylene glycol)-block-poly( $N, N$-dimethylaminoethyl methacrylate) (PEG-b-PAMA), forming a water-soluble complex that retains its secondary structure [94]. The noncovalent PEGylated L-asparaginase showed higher resistance to proteolysis by trypsin treatment and severe shaking stress, comparing with L-asparginase alone as well as covalently modified PEGylated L-asparaginase. On the other hand, two problems remained with the L-asparaginase and PEG- $b$-PAMA complex: (i) The electrostatic interaction was the main driving force between L-asparaginase and PEG- $b$-PAMA; thus, increasing the concentration of salts, typically to $150 \mathrm{mM}$ $\mathrm{NaCl}$, caused dissociation of the complex. One of the practical solutions to this problem was the design of hydrophobic groups on the cationic PAMA region [95]. (ii) Noncovalent PEGylated L-asparaginase showed lower resistance to heat treatment at $60^{\circ} \mathrm{C}$ than covalently PEGylated enzyme. This instability may have been due to the oligomeric form of this protein, because the polyelectrolyte bound to the thermally unfolded state of the tetrameric enzyme rather than to the native form. In other words, the monomeric protein may have been stabilized by the polyelectrolyte against thermal stress.

In contrast to the cationic PEG-b-PAMA complex and anionic L-asparaginase, a cationic polyelectrolyte of poly( $N, N$-diethylaminoethyl methacrylate)-graft-poly(ethylene glycol) (PEAMA-g-PEG) stabilizes the cationic enzymes, lysozyme [96] and ribonuclease A [97] against heat treatment. This phenomenon is not so surprising because (i) PEG is a kind of aggregation suppressor, (ii) PEG has the salting-out effect, and (iii) a positively charged polyelectrolyte increases the propensity of repulsion between positively charged proteins. Similar phenomena for protein stabilization have been observed for polyanions complexed with basic proteins [48]. The first point is that PEAMA-g-PEG is the aggregation suppressor of proteins. It is known that lysozyme is irreversibly inactivated during heat treatment at $98^{\circ} \mathrm{C}$ and neutral $\mathrm{pH}$ 
due to physical intermolecular interactions and chemical degradation [98]. The second point originally raised was that PEG was the superior additive for crystallization and precipitation [99]. PEG is now known to confer a salting-out effect as a preferentially excluded compound on the native protein, similar in nature to glycerol [100] and sugars [101]. It is noted that PEG tends to bind to hydrophobic protein surfaces at elevated temperatures [102-104]. The third point also relates to irreversible aggregate formation between thermally unfolded molecules. For example, oligoethylene glycols (PEG units) suppress the irreversible aggregation of $\alpha$-chymotrypsin at higher temperatures [105]. Thus, the repulsive force between complexes of cationic enzyme and cationic PEAMA-g-PEG is higher than that between enzyme molecules alone.

Recently, it has shown that large polyphosphates bind to unfolded proteins and aggregates [106], which seem to be a primordial chaperon [107]. However, in vitro stabilization of protein is favorable for PEGylated polymer without aggregation and precipitation. It was found that anionic Aspergillus oryzae $\alpha$-amylase formed precipitates with cationic PAA [49]. The aggregated $\alpha$-amylase-PAA complex was not recovered by the oppositely charged PAAc. This is because binding and aggregation of the polyelectrolyte and protein induced irreversible unfolding of the tertiary structure. Such unfolding of an enzyme is suppressed by the use of a PEGylated polymer, poly $(N, N$-diethylaminoethyl methacrylate)-block-poly(ethylene glycol) (PEAMA-b-PEG) [50]. Note that PEAMA-b-PEG has been developed for the delivery of small interfering RNA into cells $[108,109]$. As expected, $\alpha$-amylase formed a complex with PEAMA- $b$-PEG without forming aggregates, and was subsequently fully recovered by addition of the anionic polymer, PAAc. Furthermore, a large tetrameric protein, $\beta$-galactosidase (465.4 kDa, $\mathrm{p} I=5.1)$ was investigated. The $\beta$-galactosidase/PEAMA- $b$-PEG complex was soluble and inactive toward $o$-nitrophenyl- $\beta$-D-galactopyranoside as a substrate. Subsequently, the addition of an anionic PAAc almost completely recovered the enzyme from the complex with PEAMA- $b$-PEG. Thus, it was concluded that water dispersed the effects of the PEG group in the protein-polymer complex, preventing denaturation due to aggregate formation.

\section{CONCLUSION}

This review summarizes a wrap-and-strip PPC technology that enhances protein function and stability in vitro. The applications of PPCs include storage of proteins in aqueous solutions, enrichment of pharmaceutical proteins, catalytic activity switch of enzymes, hyperactivation of enzymes, and stabilization of proteins. Both insoluble and soluble PPCs have stimuli-responsive reversibility using several factors, such as $\mathrm{pH}$, ionic strength, and other proteins and polyelectrolytes. It is noted that PPC formation is versatile enough to be used for enzymes, hormone peptides, antibodies, and oligomeric large proteins. We believe that wrap-and-strip PPC technology is simple and versatile that expands the application of protein in aqueous solution.

\section{CONFLICT OF INTEREST}


The authors confirm that this article content has no conflicts of interest.

\section{ACKNOWLEDGMENT}

We thank Prof. Yukio Nagasaki for valuable discussion of this theme. The authors are grateful for financial support from University of Tsukuba.

\section{References}

[1] Yancey, P.H.; Clark, M.E.; Hand, S.C.; Bowlus, R.D.; Somero, G.N. Living with water stress: evolution of osmolyte systems. Science, 1982, 217, 1214-1222.

[2] Arakawa, T.; Timasheff, S.N. The stabilization of proteins by osmolytes. Biophys J., 1985, 47, 411-414.

[3] Greene, R.F. Jr; Pace, C.N. Urea and guanidine hydrochloride denaturation of ribonuclease, lysozyme, a-chymotrypsin, and beta-lactoglobulin. J. Biol. Chem., 1974, 249, 5388-5393.

[4] Shiraki, K.; Kudou, M.; Nishikori, S.; Kitagawa, H.; Imanaka, T.; Takagi, M. Arginine ethylester prevents thermal inactivation and aggregation of lysozyme. Eur. J. Biochem. 2004, 271, 3242-3247.

[5] Hamada, H.; Shiraki, K. L-Argininamide improves the refolding more effectively than L-arginine. $J$. Biotechnol. 2007, 130, 153-160.

[6] Shiraki, K.; Kudou, M.; Sakamoto, R.; Yanagihara, I.; Takagi M. Amino acid esters prevent thermal inactivation and aggregation of lysozyme. Biotechnol. Prog., 2005, 21, 640-643.

[7] Matsuoka, T.; Tomita, S.; Hamada, H.; Shiraki, K. Amidated amino acids are prominent additives for preventing heat-induced aggregation of lysozyme. J. Biosci. Bioeng., 2007, 103, 440-443.

[8] Okanojo, M.; Shiraki, K.; Kudou, M.; Nishikori, S.; Takagi, M. Diamines prevent thermal aggregation and inactivation of lysozyme. J. Biosci. Bioeng., 2005, 100, 556-561.

[9] Kudou, M.; Shiraki, K.; Fujiwara, S.; Imanaka, T.; Takagi, M. Prevention of thermal inactivation and aggregation of lysozyme by polyamines. Eur. J. Biochem., 2003, 270, 4547-4554.

[10] Hamada, H.; Arakawa, T.; Shiraki. K. Effect of additives on protein aggregation. Cur. Pharm. Biotech., 2009, 10, 400-407.

[11] Morawetz, H.; Hughes, W.L. Jr. The Interaction of proteins with wynthetic polyelectrolytes. I. Complexing of bovine serum albumin. J. Phys. Chem., 1952, 56, 64-69.

[12] Burgess, R.R.; Jendrisak, J.J. Procedure for the rapid, large-scale purification of Escherichia coli DNA-dependent RNA polymerase involving polymin $\mathrm{P}$ precipitation and DNA-cellulose chromatography. Biochemistry, 1975, 14, 4634-4638.

[13] Cooper, C.L.; Dubin, P.L.; Kayitmazer, A.B.; Turksen, S. Polyelectrolyte-protein complexes. Curr. Opin. Colloid Interface Sci., 2005, 10, 52-78.

[14] Kayitmazer, A.B.; Seeman, D.; Minsky, B.B.; Dubin, P.L.; Xu, Y. Protein-polyelectrolyte interactions. Soft Matter, 2013, 9, 2553-2583.

[15] Sacco, D.; Bonneaux, F.; Dellacherie, E. Interaction of haemoglobin with dextran sulphates and the 
oxygen-binding properties of the covalent conjugates. Int. J. Biol. Macromolecules, 1988, 10, 305-310.

[16] Kokufuta, E.; Shimizu, H.; Nakamura, I. Salt linkage formation of poly(diallyldimethylammonium chloride) with acidic groups in the polyion complex between human carboxyhemoglobin and potassium poly(vinyl alcohol) sulfate. Macromolecules, 1981, 14, 1178-1180.

[17] Zimet, P.; Livney, Y.D. $\beta$-Lactoglobulin and its nano-complexes with pectin as vehicles for omega-3 polyunsaturated fatty acids. Food Hydrocol., 2009, 23, 1120-1126.

[18] Gallstedt, M.; Brottman, A.; Hedenqvist, M. S. Packaging- related properties of protein- and chitosan-coated paper. Packaging Technol. Sci., 2005, 18, 161-170.

[19] Kataoka, K.; Harada, A.; Nagasaki, Y. Block copolymer micelles for drug delivery: design, characterization and biological significance. Adv. Drug. Deliv. Rev. 2001, 47, 113-131.

[20] Lee, Y.; Ishii, T.; Kim, H.J.; Nishiyama, N.; Hayakawa, Y.; Itaka, K.; Kataoka, K. Efficient delivery of bioactive antibodies into the cytoplasm of living cells by charge-conversional polyion complex micelles. Angew. Chem. Int. Ed., 2010, 49, 2552-2555.

[21] Oishi, M.; Nagasaki, Y.; Itaka, K.; Nishiyama, N.; Kataoka, K. Lactosylated poly(ethylene glycol)-siRNA conjugate through acid-labile beta-thiopropionate linkage to construct pH-sensitive polyion complex micelles achieving enhanced gene silencing in hepatoma cells. J. Am. Chem. Soc., 2005, 127, 1624-1625.

[22] Houska, M.; Brynda, E.; Bohatá, K. The effect of polyelectrolyte chain length on layer-by-layer protein/polyelectrolyte assembly-an experimental study. J. Colloid. Interface Sci., 2004, 273, 140-147.

[23] Bhardwaj, N.; Kundu, S.C. Silk fibroin protein and chitosan polyelectrolyte complex porous scaffolds for tissue engineering applications. Carbohydrate Polym., 2011, 85, 325-333.

[24] Fan, Y.; Tang, S.; Thomas, E.L.; Olsen, B.D. Responsive block copolymer photonics triggered by protein-polyelectrolyte coacervation. ACS Nano, 2014, 8, 11467-11473.

[25] de Vos, W.M.; Biesheuvel, P.M.; de Keizer, A.; Kleijn, J.M.; Stuart C.M.A. Adsorption of the protein bovine serum albumin in a planar poly(acrylic acid) brush layer as measured by optical reflectometry. Langmuir, 2008, 24, 6575-6584.

[26] Bekri, S.; Leclercq, L.; Cottet, H. Polyelectrolyte multilayer coatings for the separation of proteins by capillary electrophoresis: Influence of polyelectrolyte nature and multilayer crosslinking. J. Chromatogr. A, 2015, 1399, 80-87.

[27] Klajnert, B.; Cortijo-Arellano, M.; Cladera, J.; Bryszewska, M. Influence of dendrimer's structure on its activity against amyloid fibril formation. Biochem. Biophys. Res. Commun. 2006, 345, 21-28.

[28] Michaels, A.S.; Miekka, R.G. Polycation-polyanion complexes: Preparation and properties of poly-(vinylbenzyltrimethylammonium) poly-(styrenesulfonate). J. Phys. Chem., 1961, 6, 1765-1773.

[29] Michaels, A.S.; Falkenstein, G.L.; Schneider, N.S. Dielectric properties of polyanion-polycation complexes. J. Phys. Chem., 1965, 69, 1456-1465.

[30] Kabanov, V.A.; Kabanov, A.V. Interpolyelectrolyte and block ionomer complexes for gene delivery: physico-chemical aspects. Adv. Drug Deliv. Rev. 1998, 30, 49-60.

[31] Wang, W. Lyophilization and development of solid protein pharmaceuticals. Int. J. Pharm. 2000, 203, $1-60$. 
[32] Kurinomaru, T.; Maruyama, T.; Izaki, S.; Handa, K.; Kimoto, T.; Shiraki, K. Protein-poly(amino acid) complex precipitation for high-concentration protein formulation. J. Pharm. Sci., 2014, 103, 2248-2254.

[33] Izaki, S.; Kurinomaru, T.; Handa, K.; Kimoto, T.; Shiraki, K. Stress tolerance of antibody-poly(amino acid) complexes for improving the stability of high concentration antibody formulations. J. Pharm. Sci. 2015, 104, 2457-2463.

[34] Maruyama, T.; Izaki, S.; Kurinomaru, T.; Handa, K.; Kimoto, T.; Shiraki, K. Protein-poly(amino acid) precipitation stabilizes a therapeutic protein of L-asparaginase against physicochemical stress. J. Biosci. Bioeng. 2015, 120, 720-724.

[35] Izaki, S.; Kurinomaru, T.; Maruyama, T., Handa, K.; Kimoto, T.; Shiraki, K. Feasibility of antibody-poly(amino acid) complexes: Preparation of high-concentration antibody formulations and their pharmaceutical properties. J. Pharm. Sci. 2015, 104, 1929-1937.

[36] Shire, S.J.; Shahrokh, Z.; Liu, J. Challenges in the development of high protein concentration formulations. J. Pharm. Sci., 2004, 93, 1390-1402.

[37] Yadav, S.; Laue, TM.; Kalonia, D.S.; Singh, S.N.; Shire, S.J. The influence of charge distribution on self-association and viscosity behavior of monoclonal antibody solutions. Mol. Pharm., 2012, 9, 791-802.

[38] Mitragotri, S.; Burke, P.A.; Langer, R. Overcoming the challenges in administering biopharmaceuticals: formulation and delivery strategies. Nat. Rev. Drug. Discov., 2014, 13, 655-672.

[39] Rosenberg, E.; Hepbildikler, S.; Kuhne, W.; Winter, G. Ultrafiltration concentration of monoclonal antibody solutions: Development of an optimized method minimizing aggregation. J. Membrane Sci., 2009, 15, 50-59.

[40] Liu, J.; Nguyen, M.; Andya, J.; Shire, S. Reversible self-association increases the viscosity of a concentrated monoclonal antibody in aqueous solution. J. Pharm. Sci., 2005, 94, 1928-1940.

[41] Du, W.; Klibanov, A.M. Hydrophobic salts markedly diminish viscosity of concentrated protein solutions. Biotechnol. Bioeng., 2011, 108, 632-636.

[42] Inoue, N.; Takai, E.; Arakawa, T.; Shiraki, K. Arginine and lysine reduce the high viscosity of serum albumin solutions for pharmaceutical injection. J. Biosci. Bioeng., 2014, 117, 539-543.

[43] Inoue, N.; Takai, E.; Arakawa, T.; Shiraki, K. Specific decrease in solution viscosity of antibodies by arginine for therapeutic formulations. Mol. Pharm., 2014, 11, 1889-1896.

[44] Nishi, H.; Miyajima, M.; Nakagami, H.; Noda, M.; Uchiyama, S.; Fukui, K. Phase separation of an IgG1 antibody solution under a low ionic strength condition. Pharm. Res., 2010, 27, 1348-1360.

[45] Yang, M.X.; Shenoy, B.; Disttler, M.; Patel, R.; McGrath, M.; Pechenov, S.; Margolin, A.L. Crystalline monoclonal antibodies for subcutaneous delivery. Proc. Natl. Acad. Sci. USA. 2003, 100, 6934-6939.

[46] Johnston, K.P.; Maynard, J.A.; Truskett, T.M.; Borwankar, A.U.; Miller, M.A.; Wilson, B.K.; Dinin, A.K.; Khan, T.A.; Kaczorowski, K.J. Concentrated dispersions of equilibrium protein nanoclusters that reversibly dissociate into active monomers. ACS Nano., 2012, 6, 1357-1369.

[47] Johnson, H.R.; Lenhoff, A.M. Characterization and suitability of therapeutic antibody dense phases for subcutaneous delivery. Mol. Pharm., 2013, 10, 3582-3591.

[48] Shalova, I.N.; Asryants, R.A.; Sholukh, M.V.; Saso, L.; Kurganov, B.I.; Muronetz, V.I.; Izumrudov, V.A. 
Interaction of polyanions with basic proteins, 2(a): Influence of complexing polyanions on the thermoaggregation of oligomeric enzymes. Macromol Biosci. 2005, 15, 1184-1192.

[49] Tomita, S.; Ito, L.; Yamaguchi, H.; Konishi, G.; Nagasaki, Y.; Shiraki, K. Enzyme switch by complementary polymer pair system (CPPS). Soft Matter, 2010, 6, 5320-5326.

[50] Kurinomaru, T.; Tomita, S.; Kudo, S.; Ganguli, S.; Nagasaki, Y.; Shiraki, K. Improved complementary polymer pair system: Switching for enzyme activity by PEGylated polymers. Langmuir, 2012, 28, 4334-4338.

[51] Tomita, S.; Shiraki, K. Poly(acrylic acid) is a common non-competitive inhibitor for cationic enzymes with high affinity and reversibility. J. Polym. Sci. Part A: Polym. Chem., 2011, 49, 3835-3841.

[52] Bucur, C.B.; Sui, Z.; Schlenoff, J.B. Ideal mixing in polyelectrolyte complexes and multilayers: Entropy driven assembly. J. Am. Chem. Soc., 2006, 128, 13690-13691.

[53] Privalov, P.L.; Makhatadze, G.I. Contribution of hydration to protein folding thermodynamics. II. The entropy and Gibbs energy of hydration. J. Mol. Biol., 1993, 232, 660-679.

[54] Yu, S.; Xu, X.; Yigit, C.; van der Giet, M.; Zidek, W.; Jankowski, J.; Dzubiella, J.; Ballauff, M. Interaction of human serum albumin with short polyelectrolytes: a study by calorimetry and computer simulations. Soft Matter, 2015, 11, 4630-4639.

[55] Chandrashekar, J.; Hoon, M.A.; Ryba, N.J.; Zuker, C.S. The receptors and cells for mammalian taste. Nature, 2006, 444, 288-294.

[56] Askim, J.R.; Mahmoudi, M.; Suslick, K.S. Optical sensor arrays for chemical sensing: the optoelectronic nose. Chem. Soc. Rev., 2013, 42, 8649-8682.

[57] De, M.; Rana, S.; Akpinar, H.; Miranda, O.R.; Arvizo, R.R.; Bunz, U.H.; Rotello, V.M. Sensing of proteins in human serum using conjugates of nanoparticles and green fluorescent protein. Nat. Chem., 2009, 1, 461-465

[58] Tao Y.; Ran X.; Ren J.; Qu X. Array-based sensing of proteins and bacteria by using multiple luminescent nanodots as fluorescent probes. Small, 2014, 10, 3667-3671.

[59] Miranda, O.R.; Chen, H.T.; You, C.C.; Mortenson, D.E.; Yang, X.C.; Bunz, U.H.; Rotello, V.M. Enzyme-amplified array sensing of proteins in solution and in biofluids. J. Am. Chem. Soc., 2010, 132, 5285-5289.

[60] Tomita, S.; Yoshimoto, K. Polyion complex libraries possessing naturally occurring differentiation for pattern-based protein discrimination. Chem. Commun., 2013, 49, 10430-10432.

[61] Tomita, S.; Soejima, T.; Shiraki, K.; Yoshimoto, K. Enzymatic fingerprinting of structurally similar homologous proteins using polyion complex library constructed by tuning PEGylated polyamine functionalities. Analyst, 2014, 139, 6100-6103.

[62] Tomita, S.; Yokoyama, S.; Kurita, R.; Niwa, O.; Yoshimoto, K. The use of an enzyme-based sensor array to fingerprint proteomic signatures of sera from different mammalian species. Anal. Sci., in press.

[63] Tomita, S.; Sakao, M.; Kurita, R.; Niwa, O.; Yoshimoto, K. A polyion complex sensor array for markerless and noninvasive identification of differentiated mesenchymal stem cells from human adipose tissue. Chem. Sci., 2015, 6, 5831-5836.

[64] Kurinomaru, T.; Tomita, S.; Hagihara, Y.; Shiraki, K. Enzyme hyperactivation system based on a 
complementary charged pair of polyelectrolytes and substrates. Langmuir, 2014, 30, 3826-3831.

[65] Roy, R.; Sandanaraj, B.S.; Klaikherd, A.; Thayumanavan, S. Tuning substrate selectivity of a cationic enzyme using cationic polymers. Langmuir, 2006, 22, 7695-7700.

[66] Kawamura, A.; Yoshioka, Y.; Harada, A.; Kono, K. Acceleration of enzymatic reaction of trypsin through the formation of water-soluble complexes with poly(ethylene glycol)-block-poly( $\alpha, \beta$-aspartic acid). Biomacromol., 2005, 6, 627-631.

[67] Shiraki, K.; Norioka, S.; Li, S.; Sakiyama, F. Contribution of an imidazole-indole stack to high catalytic potency of a lysine-specific serine protease, Achromobacter protease I. J. Biochem., 2002, 131, 213-218.

[68] Shiraki, K.; Norioka, S.; Li, S.; Yokota, K.; Sakiyama, F. Electrostatic role of aromatic ring stacking in the $\mathrm{pH}$-sensitive modulation of a chymotrypsin-type serine protease, Achromobacter Protease I. Eur. J. Biochem., 2002, 269, 4152-4158.

[69] Kurinomaru, T.; Kameda, T.; Shiraki, K. Effects of hydrophobicity and multivalency of polyamines on enzyme hyperactivation of alpha-chymotrypsin. J. Mol. Catal. B: Enzymatic, 2015, 115, 135-139.

[70] Alfani, F.; Viparelli, P.; Alfani, F.; Gallifuoco, A.; Cantarella, M. Effect of quaternary ammonium salts on the hydrolysis of N-glutaryl-l-phenylalanine catalysed by $\alpha$-chymotrypsin. J. Mol. Catal. B: Enzymatic, 2004, 28, 101-110.

[71] Viparelli, P.; Alfani, F.; Cantarella, M. Models for enzyme superactivity in aqueous solutions of surfactants. Biochem. J., 1999, 344, 765-773.

[72] Viparelli, P.; Alfani, F.; Cantarella, M. Experimental validation of a model for alpha-chymotrypsin activity in aqueous solutions of surfactant aggregates. J. Mol. Catal. B: Enzymatic, 2001, 15, 1-8.

[73] Abuchowski, A.; van Es, T.; Palczuk, N.C.; Davis, FF. Alteration of immunological properties of bovine serum albumin by covalent attachment of polyethylene glycol. J. Biol. Chem., 1977, 252, 3578-3581.

[74] Monfardini, C.; Schiavon, O.; Caliceti, P.; Morpurgo, M.; Harris, J.M.; Veronese, F.M. A ranched mono-methoxy-poly(ethylene glycol) for protein modification. Bioconjug. Chem., 1995, 6, 62-69.

[75] Chapman, A.P. PEGylated antibodies and antibody fragments for improved therapy: A review. Adv. Drug Deliv. Rev., 2002, 54, 531-545.

[76] Katre, N.V.; Knauf, M.J.; Laird, W.J. Chemical modification of recombinant interleukin 2 by polyethylene glycol increases its potency in the murine Meth A sarcoma model. Proc. Natl. Acad. Sci. USA, 1987, 84, 1487-1491.

[77] Harris, J.M.; Chess, R.B. Effect of PEGylation on pharmaceuticals. Nat. Rev. Drug Discov., 2003, 2, 214-221.

[78] Pfister, D.; Morbidelli, M. Process for protein PEGylation. J. Control. Release, 2014, 180, 134-149.

[79] Roberts, M.J.; Bentley, M.D.; Harris, J.M. Chemistry for peptide and protein PEGylation. Adv. Drug Deliv. Rev., 2002, 54, 459-476.

[80] Greenwald, R.B.; Choe, Y.H.; McGuire, J.; Conover, C.D. Effective drug delivery by PEGylated drug conjugates. Adv. Drug Deliv. Rev., 2003, 55, 217-250.

[81] Mueller, C.; Capelle, M.A.; Arvinte, T.; Seyrek, E.; Borchard, G. Noncovalent PEGylation by dansyl-poly(ethylene glycol)s as a new means against aggregation of salmon calcitonin. J. Pharm. Sci., 
2011, 100, 1648-1662.

[82] Mueller, C.; Capelle, M.A.; Arvinte, T.; Seyrek, E.; Borchard, G. Tryptophan-mPEGs: novel excipients that stabilize salmon calcitonin against aggregation by non-covalent PEGylation. Eur. J. Pharm. Biopharm., 2011, 79, 646-657.

[83] Mero, A.; Ishino, T.; Chaiken, I.; Veronese, F.M.; Pasut, G. Multivalent and flexible PEG-nitrilotriacetic acid derivatives for non-covalent protein PEGylation. Pharm. Res., 2011, 28, 2412-2421.

[84] Lee, H.; Park, T.G. A novel method for identifying PEGylation sites of protein using biotinylated PEG derivatives. J. Pharm. Sci., 2003, 92, 97-103.

[85] Khondee S.; Olsen C.M.; Zeng Y.; Middaugh C.R.; Berkland C. Noncovalent PEGylation by polyanion complexation as a means to stabilize keratinocyte growth factor-2 (KGF-2). Biomacromol., 2011, 12, 3880-3894.

[86] Pourhosseini, P.S.; Saboury, A.A.; Najafi, F.; Sarbolouki, M.N. Interaction of insulin with a triblock copolymer of PEG-(fumaric-sebacic acids)-PEG: thermodynamic and spectroscopic studies. Biochim. Biophys. Acta. 2007, 1774, 1274-1280.

[87] Bayat, A.; Dorkoosh, FA.; Dehpour, A.R.; Moezi, L.; Larijani, B.; Junginger, H.E.; Rafiee-Tehrani, M. Nanoparticles of quaternized chitosan derivatives as a carrier for colon delivery of insulin: ex vivo and in vivo studies. Int. J. Pharm., 2008, 356, 259-266.

[88] Pastor, E.; Matveeva, E.; Valle-Gallego, A.; Goycoolea, F.M.; Garcia-Fuentes, M. Protein delivery based on uncoated and chitosan-coated mesoporous silicon microparticles. Colloids Surf. B, Biointerfaces, 2011, 88, 601-609.

[89] Tsiourvas, D.; Sideratou, Z.; Sterioti, N.; Papadopoulos, A.; Nounesis, G.; Paleos, C.M. Insulin complexes with PEGylated basic oligopeptides. J. Colloid Interface Sci., 2012, 384, 61-72.

[90] Thompson, C.J.; Tetley, L.; Uchegbu, I.F.; Cheng, W.P. The complexation between novel comb shaped amphiphilic polyallylamine and insulin: towards oral insulin delivery. Int. J. Pharm., 2009, 376, 46-55.

[91] Oettgen, H.F.; Old, L.J.; Boyse, E.A.; Campbell, H.A.; Philips, F.S.; Clarkson, B.D.; Tallal, L.; Leeper, R.D.; Schwartz, M.K.; Kim, J.H. Inhibition of leukemias in man by L-asparaginase. Cancer Res., 1967, 27, 2619-2631.

[92] Huber, R.; Epp, O.; Steigemann, W.; Formanek, H. The atomic structure of erythrocruorin in the light of the chemical sequence and its comparison with myoglobin. Eur. J. Biochem., 1971, 19, 42-50.

[93] Swain, A.L.; Jaskólski, M.; Housset, D.; Rao, J.K.; Wlodawer, A. Crystal structure of Escherichia coli L-asparaginase.; an enzyme used in cancer therapy. Proc. Natl. Acad. Sci. USA, 1993, 90, 1474-1478.

[94] Kurinomaru, T.; Shiraki, K. Noncovalent PEGylation of L-asparaginase using PEGylated polyelectrolyte. J. Pharm. Sci., 2015, 104, 587-592.

[95] Otsuka, H.; Nagasaki, Y.; Kataoka, K. PEGylated nanoparticles for biological and pharmaceutical applications. Adv. Drug Deliv. Rev. 2003, 55, 403-419.

[96] Ganguli, S.; Yoshimoto, K.; Tomita, S.; Sakuma, H.; Matsuoka, T.; Shiraki, K.; Nagasaki, Y. Regulation of lysozyme activity based on thermotolerant protein/smart polymer complex formation. J. Am. Chem. Soc., 2009, 131, 6549-6553.

[97] Ganguli, S.; Yoshimoto, K.; Tomita, S.; Sakuma, H.; Matsuoka, T.; Shiraki, K.; Nagasaki, Y. 
Improving the heat resistance of ribonuclease A by the addition of poly(N,N-diethylaminoethyl methacrylate)-graft-poly(ethylene glycol) (PEAMA-g-PEG). Macromol. Biosci., 2010, 10, 853-859.

[98] Tomita, S.; Shiraki, K. Why do solution additives suppress the heat-induced inactivation of proteins? inhibition of chemical modifications. Biotechnol. Prog. 2011, 27, 855-862.

[99] McPherson, A Jr. Crystallization of proteins from polyethylene glycol. J. Biol. Chem., 1976, 251, 6300-6303.

[100] Gekko, K.; Timasheff, S.N. Mechanism of protein stabilization by glycerol: preferential hydration in glycerol-water mixtures. Biochemistry, 1981, 20, 4667-4676.

[101] Arakawa, T.; Timasheff, S.N. Stabilization of protein structure by sugars. Biochemistry, 1982, 21, 6536-6544.

[102] Lee, L.L.; Lee, J.C. Thermal stability of proteins in the presence of poly(ethylene glycols). Biochemistry, 1987, 26, 7813-7819.

[103] Bhat, R.; Timasheff, S.N. Steric exclusion is the principal source of the preferential hydration of proteins in the presence of polyethylene glycols. Protein Sci., 1992, 1, 1133-1143.

[104] Tubio, G.; Nerli, B.; Picó, G. Relationship between the protein surface hydrophobicity and its partitioning behaviour in aqueous two-phase systems of polyethyleneglycol-dextran. J. Chromatogr. B, Analyt. Technol. Biomed. Life Sci., 2004, 799, 293-301.

[105] Tomita, S.; Tanabe, Y.; and Shiraki, K. Oligoethylene glycols prevent thermal aggregation of alpha-chymotrypsin in a temperature-dependent manner: Implications for design guidelines. Biotechnol. Prog. 2013, 29, 1325-1330.

[106] Semenyuk, P.I.; Moiseeva, E.V.; Stroylova, Y.Y.; Lotti, M.; Izumrudov, V.A.; Muronetz, V.I. Sulfated and sulfonated polymers are able to solubilize efficiently the protein aggregates of different nature. Arch. Biochem. Biophys. 2015, 567, 22-29.

[107] Gray, M.J.; Wholey, W.Y.; Wagner, N.O.; Cremers, C.M.; Mueller-Schickert, A.; Hock, N.T.; Krieger, A.G.; Smith, E.M.; Bender, R.A.; Bardwell, J.C.; Jakob, U. Polyphosphate is a primordial chaperone. Mol. Cell, 2014, 53, 689-699.

[108] Tamura, A.; Oishi, M.; Nagasaki, Y. Enhanced cytoplasmic delivery of siRNA using a stabilized polyion complex based on PEGylated nanogels with a cross-linked polyamine structure. Biomacromolecules, 2009, 10, 1818-1827.

[109] Tamura, A.; Oishi, M.; Nagasaki, Y. Efficient siRNA delivery based on PEGylated and partially quaternized polyamine nanogels: enhanced gene silencing activity by the cooperative effect of tertiary and quaternary amino groups in the core. J. Control Release, 2010, 146, 378-387. 


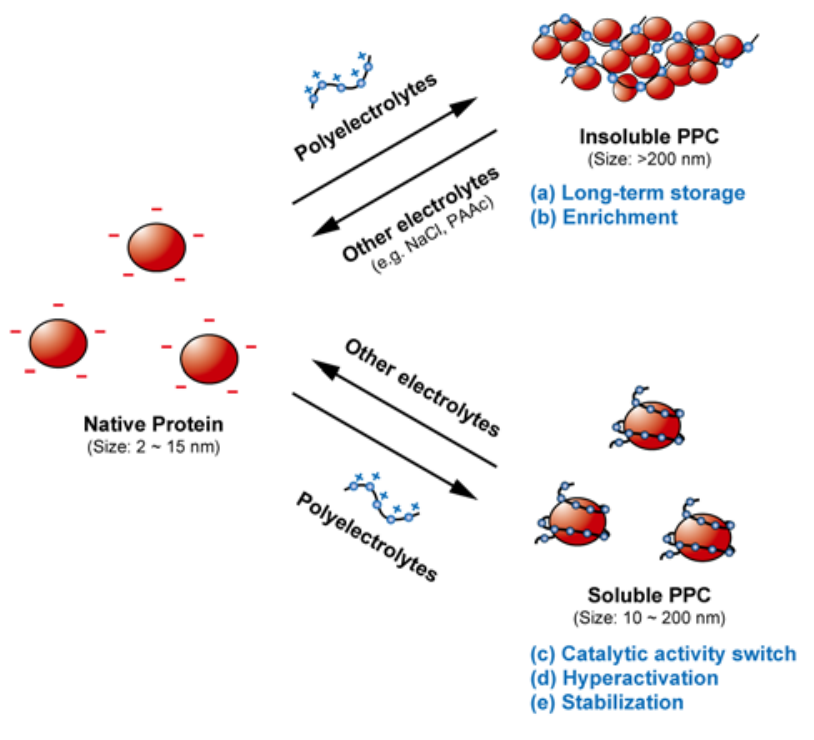

Figure 1: Overview of this review for "wrap-and-strip" technology of protein-polyelectrolyte complex (PPC). Insoluble PPC is used for an enrichment and stabilization of protein. Soluble PPC is used for catalytic activity switch, hyperactivation, and stabilization.

Step1: Solution

Step2: Suspension

Step3: Precipitation

Step4: Concentration

Step5: Redissolution


B

\begin{tabular}{|l|}
\hline [Protein] \\
$30 \mathrm{mg} / \mathrm{mL}$ Adalimumab \\
\hline [Poly(amino acid)] \\
$0 \mathrm{mg} / \mathrm{mL}$ PolyE \\
\hline$[\mathrm{NaCl}]$ \\
$0 \mathrm{mM} \mathrm{NaCl}$ \\
\hline Solvent \\
$10 \mathrm{mM}$ MOPS $(\mathrm{pH} 6.5)$ \\
\hline Total volume \\
$200 \mu \mathrm{L}$ \\
\hline
\end{tabular}

\begin{tabular}{|c|}
\hline $\begin{array}{l}\text { [Protein] } \\
15 \mathrm{mg} / \mathrm{mL} \text { Adalimumab }\end{array}$ \\
\hline $\begin{array}{l}\text { [Poly(amino acid)] } \\
1.5 \mathrm{mg} / \mathrm{mL} \text { PolyE }\end{array}$ \\
\hline $\begin{array}{l}{[\mathrm{NaCl}]} \\
0 \mathrm{mM} \mathrm{NaCl}\end{array}$ \\
\hline $\begin{array}{l}\text { Solvent } \\
10 \mathrm{mM} \text { MOPS (pH 6.5) }\end{array}$ \\
\hline $\begin{array}{l}\text { Total volume } \\
400 \mu \mathrm{L}\end{array}$ \\
\hline
\end{tabular}

\begin{tabular}{|l|}
\hline [Protein] \\
$15 \mathrm{mg} / \mathrm{mL}$ Adalimumab \\
\hline [Poly(amino acid)] \\
$1.5 \mathrm{mg} / \mathrm{mL}$ PolyE \\
\hline$[\mathrm{NaCl}]$ \\
$0 \mathrm{mM} \mathrm{NaCl}$ \\
\hline Solvent \\
$10 \mathrm{mM}$ MOPS $(\mathrm{pH} 6.5)$ \\
\hline Total volume \\
$400 \mu \mathrm{L}$ \\
\hline
\end{tabular}

\begin{tabular}{|l|}
\hline $\begin{array}{l}\text { [Protein] } \\
200 \mathrm{mg} / \mathrm{mL} \text { Adalimumab }\end{array}$ \\
\hline $\begin{array}{l}\text { [Poly(amino acid)] } \\
20 \mathrm{mg} / \mathrm{mL} \text { PolyE }\end{array}$ \\
\hline $\begin{array}{l}\text { [NaCl] } \\
0 \mathrm{mM} \mathrm{NaCl}\end{array}$ \\
\hline $\begin{array}{l}\text { Solvent } \\
10 \mathrm{mM} \text { MOPS }(\mathrm{pH} 6.5)\end{array}$ \\
\hline Total volume \\
$30 \mu \mathrm{L}$ \\
\hline
\end{tabular}

\begin{tabular}{|l|}
\hline $\begin{array}{l}\text { [Protein] } \\
150 \mathrm{mg} / \mathrm{mL} \text { Adalimumab }\end{array}$ \\
\hline [Poly(amino acid)] \\
$15 \mathrm{mg} / \mathrm{mL}$ PolyE \\
\hline [NaCl] \\
$150 \mathrm{mM} \mathrm{NaCl}$ \\
\hline Solvent \\
$10 \mathrm{mM}$ MOPS $(\mathrm{pH} 6.5)$ \\
\hline Total volume \\
$40 \mu \mathrm{L}$ \\
\hline
\end{tabular}

Figure 2: Concentration method of protein by poly(amino acid). (A) Protein solution is suspended by poly(glutamic acid) (PolyE), followed by the centrifuged protein is obtained. The precipitated state is a kind of concentrated state that stabilizes physical and chemical stresses. More importantly, the concentrated-state protein is easily resolubilized by addition of salt. (B) A typical solution condition. Here, $30 \mathrm{mg} / \mathrm{ml}$ Adalimumab is concentrated at $150 \mathrm{mg} / \mathrm{ml}$ for a few minutes under the physiological solution condition. 


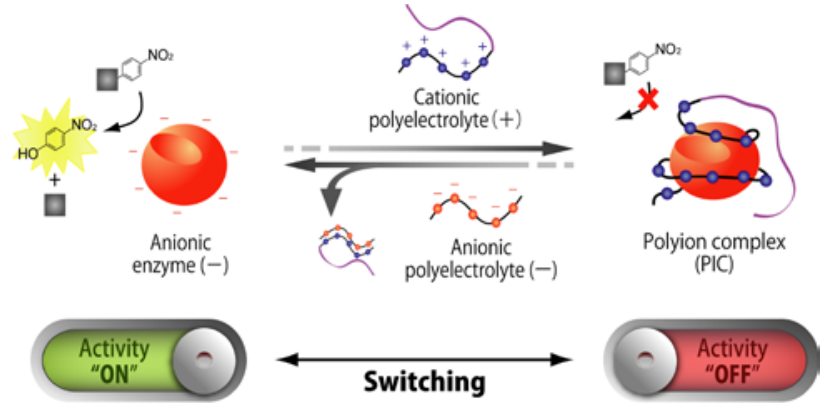

Figure 3: Schematic diagram of enzyme function switch by complementary polymer pair. (Upper) Negatively charged enzyme is inactivated by positively charged polyelectrolyte, followed by reactivated by negatively charged polyelectrolyte, and vise versa. (Lower) The enzyme switch represents the image of toggle switch of an electric light in our room.



Figure 4: The gustatory system (A) and mimicked sensing system (B). The catalytic activity of cross-reactive PPCs was reactivated by the addition of analyte proteins, generating unique response patterns of changes in enzyme activity. Multivariate analysis of obtained response patterns enabled the discrimination of analyte proteins. 


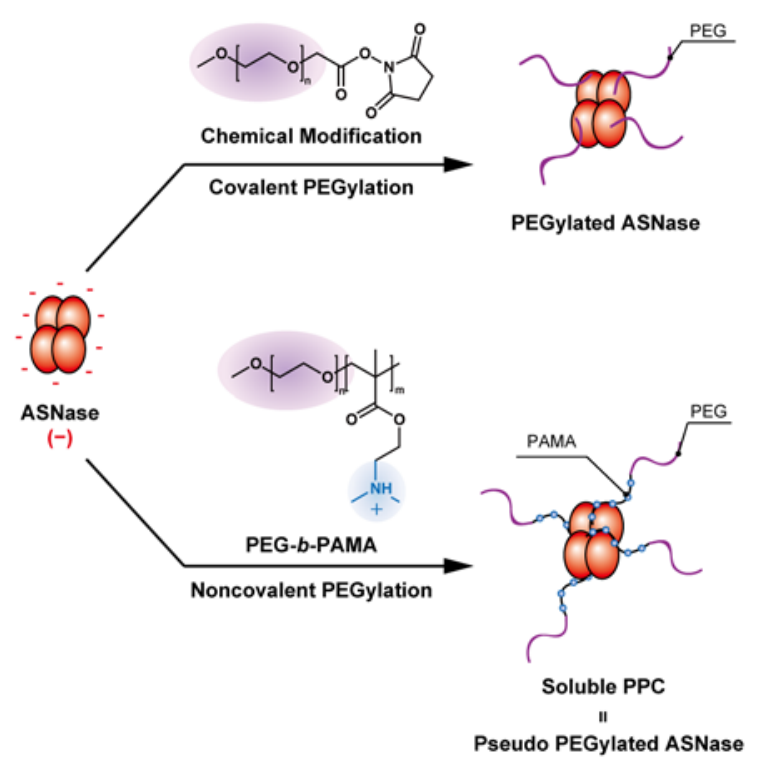

Figure 5: PEGylation with covalent and noncovalent approaches. Upper image shows direct chemical modification of PEG on L-asparginase (ASNase) surface, leading to stabilization of the enzyme. Lower image shows PEG-modified polyelectrolyte bound on ASNase by noncovalent binding, which gives the stability in aqueous solution. PAMA; poly(N,N-dimethylaminoethyl methacrylate). PEG- $b$-PAMA; poly(ethylene glycol)-block-poly( $N, N$-dimethylaminoethyl methacrylate). 